\title{
Improvement in Yield Strength of Deformed Steel Bar by Quenching Using Taguchi Method
}

\author{
Manojkumar S.Lakal ${ }^{1}$, Dr.S.B.Chikalthankar ${ }^{2}$ \\ ${ }^{I}$ (Lecturer in Mechanical Engineering, Government Polytechnic, Jalna, Maharashtra State, India.) \\ ${ }_{2}^{2}$ (Asstt.Prof. in Mechanical Engineering, Govt. College of Engineering, Aurangabad, Maharashtra State, India)
}

\begin{abstract}
This paper is on improvement in Yield strength of deformed steel bar by quenching using Design of experiment (DOE) for robust process design. The production of high quality deformed steel bar for concrete reinforcement will reduce the construction cost. It is found that the bar produced having variation in yield strength, this major quality problem is considered for improvement. Yield strength of bar is deviated from standard value specified in IS: 1786-1985. Here the study is focused on the robust parameter design for cooling system, to control the process of quenching to get the desired Yield strength of deformed steel bar. The controlling parameters of cooling system were controlled to improve the Yield strength of bar produced. Taguchi method of Orthogonal Array was used to find the effect of parameter on output quality parameter such as yield strength. DOE by Taguchi approach was used for the improvement in Yield strength. We got satisfactory result of yield strength of deformed steel bar having minimum variation from its mean value. Thus the Yield strength of bar has been improved by controlling the Quenching process parameters at optimum level which was found from factor effect plot using DOE by Taguchi Method.
\end{abstract}

Keywords: Rolling, Quenching, Taguchi method, Yield strength, Robust design, Deformed steel bar.

\section{Introduction}

In this paper, the study of hot bar quenching process has been investigated. In order to predict the effect of noise factors and signal on response factor of water quenching process. The controlling parameters such as water pressure, speed of rolling, Cooling rate and Finish rolling temperature of bar were the four independent factors and each of them have three levels were considered for DOE and the response was yield strength. An orthogonal array- $\mathrm{L}_{9}$ had been used for the experiment. Here we used DOE by Taguchi method of orthogonal array to find the effect of parameter on Yield strength. Before conducting the experiment, the quenching setup was made ready with all respect to conduct experiment. The experiments were conducted and experimental data was recorded and analyzed by excel statistical method. The graph of main effect plot of factors was drawn, which was used to find the main effect on response. The parameters were controlled properly to minimize variation in yield strength and obtained the desired quality of bar. Here it is found that water pressure had the largest effect on the yield strength. The water pressure was controlled at different level for many experiments as per L-9 array and yield strength for each experiment was noted. The experimental data analyses were done by Minitab Statistical software. We found the optimum level of parameters setting to get optimum level of Yield strength. For this action plan was designed to control water pressure to a specific level as per the conclusion of this experimentation. Then the action plan had been implemented. The deformed bar were produced and checked for its quality; we found satisfactory quality steel bar having optimum Yield strength. The conclusion has been found that the cooling rate affects on yield strength, but cooling rate is controlled by water pressure which is operated using control valve. Hence water pressure has been controlled in quenching process to get the desired quality with minimum variation from standard value. The bar of $8 \mathrm{~mm}$ was produced by controlled rolling and quenching process. Speed of rolling was kept constant and PLC control water pressure valve was used instead of manual control valve for controlling the water pressure.

\section{Cooling system}

For the given operation conditions, the temperature and its distribution within the bar entering into the quenching play the crucial role in controlling the mechanical properties of the steel bar such as yield strength. Hence understanding of the cooling system is essential. There are three types of most frequently used cooling system in hot rolling; water jet cooling system, water spray cooling system, and mist cooling systems.[3]It is found that, the yield strength depends on cooling rate. Hence to control cooling rate we made the modification in the present system. The water pressure need to be controlled according the speed of rolling of bar and temperature of bar before entering the quenching system. Fig. 1 shows the cooling system having water injector, a cooling tube, and a water stripper. As per size of bar to be produced, the length of cooling pipe is selected and the speed of rolling is controlled accurately.Fig.2, shows water pressure control valve in cooling system, the primary and secondary valves are used to control the water supply, another valve is used to control the air 
Improvement in Yield Strength of Deformed Steel Bar by Quenching using Taguchi Method

supply of the cooling system which helps to dry the rod surface after quenching process. Cooling elements operate according to the continuous flow principle. Water supply is provided with two nozzles located one after another. A chamber is provided in front of the nozzle chamber in cooling system.PLC operated valve on the return line makes it possible to adjust the auxiliary water flow accurately. Upon proper adjustment of valve water flow rate will remain constant. The guide pieces lead the rolling stand and cause turbulence in the cooling medium. The backwater chamber is connected to the venturi guide and most of the cooling water is being discharged upward through a bend. A deflection chamber is the end portion of the cooling element, where pressurized water is conveyed downwards. An air stripper is placed on the exit side of the tube and cleans out a visible vapor film dragging on the outgoing stock surface from the tube. For the water stripper valves, one is used for lower pressure water stripper and the other for a higher pressure water stripper. A water injector valve is placed between them.[2]

The cooling rate of stock in the cooling system of the bar mill depends on various operation parameters such as stock size, stock delivering speed, stock temperature, water flow rate, nozzle size, and nozzle shape. Since the governing heat transfer equation for the heat exchange between the cooling water and the hot stock is well established, this typically involves a combined radiation and convection heat transfer. There are some reports that review experimental means of measuring heat-transfer coefficients and summarizing the equations for the heat transfer coefficients that can be used in the hot rolling process. [4]In the quenching process, there are three stages of cooling as follows. Vapour-blanket cooling stage in which, the temperature of bar is so high that the quenching medium is vaporized at the surface of metal and a thin stable film of vapour surrounds the hot metal. Bar is cooled by conduction and radiation through the gaseous film and since vapour films are poor heat conductors, the cooling rate is relatively slow through this stage. Vapour transport cooling stage starts when the metal has cooled to temperature at which the vapour film is no longer stable.

The vapour-blanket is broken intermittently which allows liquid to touch the hot metal at one instant but soon being pushed away from it by vapour bubble. The bubble escape from the surface and the liquid touches the hot metal again. In this stage, since hot metal surface is wetted by the quenching liquid, violent boiling occurs on the surface of metal being cooled. Very rapid cooling takes place in this stage that soon brings the metal surface temperature below the boiling point of the liquid. Liquid cooling stage is the third stage begins when the metal surface temperature just reaches the boiling of the quenching liquid .cooling in this stage takes place by simple convection and conduction. The rate of cooling decreases as the temperature of metal falls. The rate of cooling is slowest in this stage. [6]

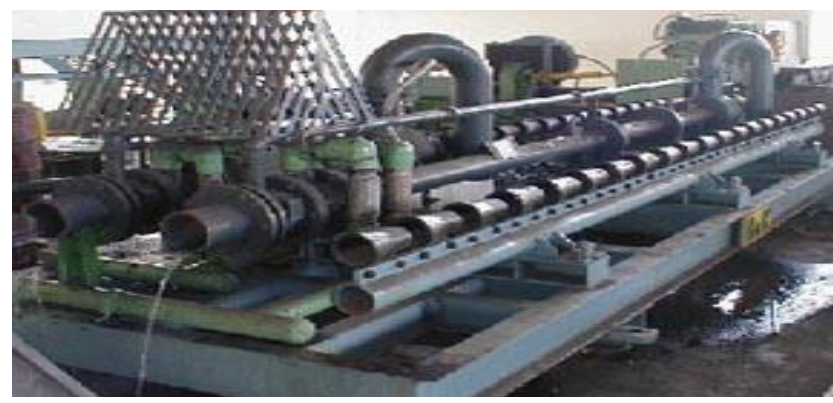

Fig.1: Shows cooling system



Fig.2: Shows water pressure control valve in cooling system

\subsection{Improvement in yield strength by quenching}

Yield strength of deformed steel bar depends on hardness of surface achieved by quenching and tempering process. Decremental hardening is the process of increasing surface hardness without change in the chemical composition of the surface. Quenching and tempering process is the heat treatment process which is 
Improvement in Yield Strength of Deformed Steel Bar by Quenching using Taguchi Method

commonly used in order to obtain tempered martensite microstructure, which has good hardness. After the quenching we get the surface hard due to martensite and core remains soft of bainite. [7].The cooling rate affects on Yield strength which depends upon surface hardness. The steel bar is at high temperature, when immersed in a water medium, vapour blanket forms at the surface of the steel which slow down the rate of heat transfer from the steel to the medium. Agitation or movement of the steel relative to medium removes the vapour blanket and thus increase the rate of cooling. The parameter selected for experimentation which directly related to cooling process are water pressure ,speed of rolling bar, finish rolling temperature, cooling rate. [3]

Quenching and Self Tempering Steel Bars has ferrite and pearlite structure at the core and tempered martensite at the surface is shown in Fig.5.Hence the bar has hard surface and soft core can helps to increase the yield strength.

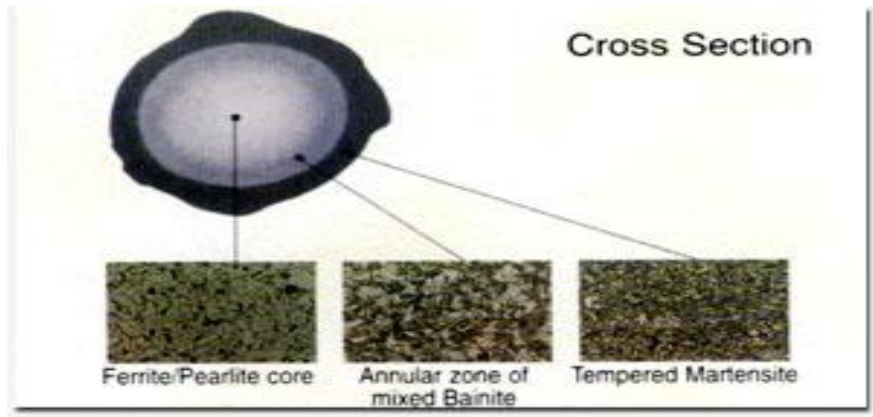

Fig.5: Shows the microstructure at surface and core.

\subsection{Rapid cooling effect on yield strength}

Rapid cooling is carried out in order to obtain martensite in hardened steel. Austenite to pearlite or bainite transformation is suppressed in this process. This means that higher cooling rates will be required only in that temperature range within which unstable austenite decomposes to ferrite-cementite aggregate. Once this range is crossed, austenite will transform to martensite even on slow cooling. Therefore, it is not essential to rapidly cool the steel component throughout the complete range of temperature from hardening temperature to quenching medium temperature. Minimum possible cooling rate will develop the lowest internal stresses in the hardened steel. Large magnitude of internal stresses may either lead to distortion of piece or to the formation of internal or external cracks.

\subsection{Testing of microstructure of deformed steel bar}

The aim of this testing is to investigate $8 \mathrm{~mm}$ TMT Steel bars before quenching and after quenching process to find the change in microstructure. This change in microstructure after quenching increase its hardness and hence increase its Yield strength. We observed that before Heat Treatment, the surface micro-structure shows Pearlitic phase (dark colour) around ferrite phase (light colour). The structure shows around 15 to $20 \%$ pearlite and remaining ferrite. This is shown in Fig.6(a) and Fig.6(c).Also we observed that after Heat Treatment, the surface micro-structure shows there is transformation in to martensite and the \% martensite is around $40 \%$, remaining untransformed phase like ferrite and retain austenite, the benitic phase are also seen at certain places. $40 \%$ martensitic phase led to rise in Hardness and tensile strength. This is shown in Fig.6 (b) and Fig.6 (d).The tempering process is occurred and the resultant bar structure is of tempered martensite at the periphery and fine grained ferrite-pearlite at the core. The final steel bar cross section is shown in Fig.5.The Fig.7 (a) and Fig. 7(b) shows the hardness before quenching is 180 to 200HV this is increased after quenching upto 300 to $320 \mathrm{HV}$. This can help to increase the Yield strength.

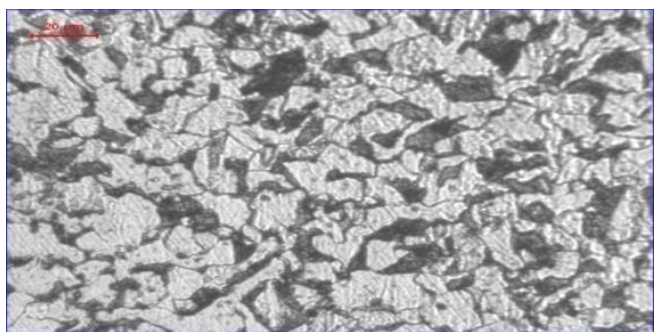

Fig 6(a) 200X Nital Core structure before Quenching. 


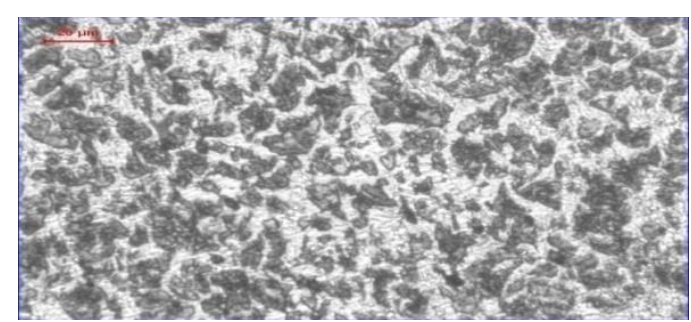

Fig 6(b) 200X Nital Core structure after Quenching.

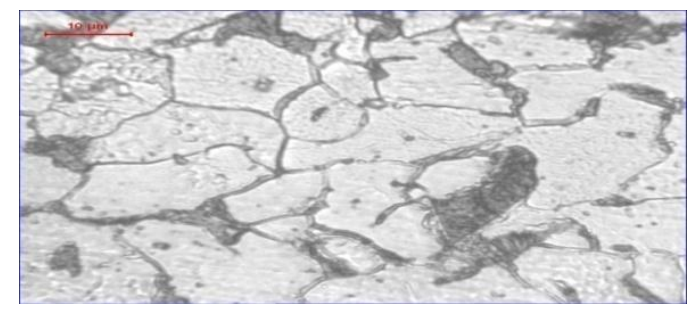

Fig 6(c) 500X Nital Core structure before quenching.

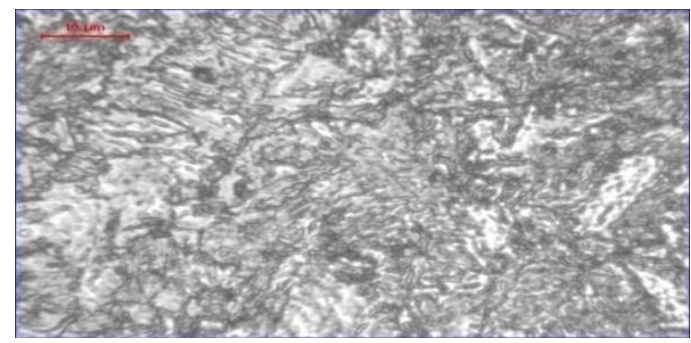

Fig 6(d) 500X Nital Core structure after quenching.

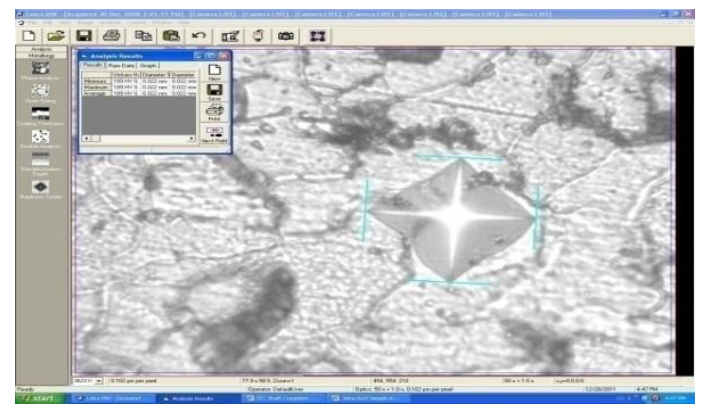

Fig 7(a) 500X Nital.MicroHardnesss189 200Hv, Before Quenching.

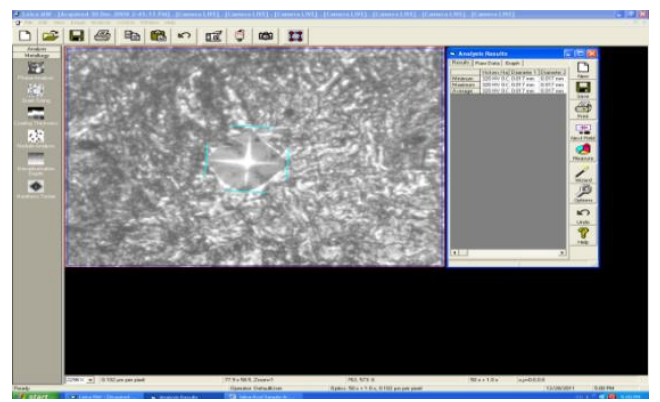

Fig 7(b) 500X Nital.MicroHardnesss $300 \sim 320 \mathrm{Hv}$,After Quenching. 


\subsection{Taguchi method for parameter design}

Taguchi's parameter design method is a powerful tool for optimizing the performance characteristic of a product/ process. The aim of a parameter design experiment is to identify and design of setting of the process parameters that optimize the chosen quality characteristics and are least sensitive to noise (uncontrollable) factors. In the present study, the goal is to evaluate the effects of process parameters on the yield strength and the optimum combination of control factors that would maximize the Yield strength Selection of control factors and their levels were made on the basis of some preliminary trial experiments conducted and also from literature review on the subject. Four control factors such as water pressure, speed of bar cooling rate and Temperature of bar before quenching were selected for the study. Each of the four control factor was treated at three levels as shown in Table1.

\section{Design of experiment}

The experiments were designed based on the orthogonal array technique. An orthogonal is fractional factorial design with pair wise balancing property. Using orthogonal array design the effects of multiple process variables on the performance characteristics can be estimated simultaneously while minimizing the number of test runs. An $\mathrm{L}_{9}$ standard orthogonal array is shown in Table 2 was employed for present investigation.

Table 3 represent the layout of the experimental design, which has been obtained by assigning the selected factors and their levels to appropriate column of L9 orthogonal array .This array has 9 rows and 4 columns and each row represents a trial condition while each column accommodates a specific process parameter. Moreover, the notation $3^{4}$ implies that at most 4 factors, each at 3 levels can be investigated using this $\mathrm{OA}$ and their main effect can be estimated provided all other interactions are negligible which is assumed in the present case. The numbers in each column indicate the levels of specific factors $\mathrm{Wp}, \mathrm{CR}, \mathrm{Sb}$ and $\mathrm{Tb}$. However, while conducting the experiments the test runs have been randomly made to avoid the unidentified noise sources, which are not considered but could have an adverse impact on the response characteristic.

Once the orthogonal array is selected, the experiments are conducted as per the level combinations. The performance parameter under study is noted down for each experiment to conduct the sensitivity analysis. The experimental setup was made ready and conducted the experiments. The data were recorded for analysis.

In the graph, it can be seen that water pressure has the largest effect on the yield strength and that temperature has the smallest effect on the yield strength. From the above experimental analysis, it is clear that the higher the value of delta of an independent variable, the more it has influence on the performance parameter. Once the experimental design has been determined and the trials have been carried out, the measured performance characteristic from each trial can be used to analyze the relative effect of the different parameters. The experiments were conducted and data is recorded and analyzed.

Table1: Control factors and its levels

\begin{tabular}{|l|c|c|c|c|}
\hline Factors & $\begin{array}{l}\text { Factor } \\
\text { designation }\end{array}$ & $\begin{array}{l}\text { Level1 } \\
(-1)\end{array}$ & $\begin{array}{l}\text { Level 2 } \\
(0)\end{array}$ & $\begin{array}{l}\text { Level 3 } \\
(+1)\end{array}$ \\
\hline Speed of bar $(\mathrm{mps})$ & $\mathrm{S}_{\mathrm{b}}$ & 11 & 13 & 15 \\
\hline Temp. of bar $\left({ }^{0} \mathrm{C}\right)$ & $\mathrm{T}_{\mathrm{b}}$ & 750 & 800 & 850 \\
\hline $\begin{array}{l}\text { Water pressure } \\
\left(\mathrm{Kgf} / \mathrm{cm}^{2}\right)\end{array}$ & $\mathrm{Wp}$ & 10 & 12 & 14 \\
\hline Cooling rate $\left({ }^{0} \mathrm{C} / \mathrm{s}\right)$ & $\mathrm{CR}$ & 80 & 100 & 120 \\
\hline
\end{tabular}

Table2: Control factors and standard orthogonal array

\begin{tabular}{|c|l|l|l|l|}
\hline Expt.No. & $\begin{array}{l}\text { water } \\
\text { pressure(Wp) } \\
\mathrm{kgf} / \mathrm{cm}^{2}\end{array}$ & $\begin{array}{l}\text { cooling } \\
\text { rate(CR) } \\
{ }^{0} \mathrm{C} / \mathrm{S}\end{array}$ & $\begin{array}{l}\text { speed of } \\
\text { rolling } \\
(\mathrm{Sb}) \mathrm{mps}\end{array}$ & $\begin{array}{l}\text { Temp. of } \\
\text { bar (Tb) } \\
{ }^{0} \mathrm{C}\end{array}$ \\
\hline 1 & 1 & 1 & 1 & 1 \\
\hline 2 & 1 & 2 & 2 & 2 \\
\hline 3 & 1 & 3 & 3 & 3 \\
\hline 4 & 2 & 1 & 2 & 3 \\
\hline 5 & 2 & 2 & 3 & 1 \\
\hline 6 & 2 & 3 & 1 & 2 \\
\hline 7 & 3 & 1 & 3 & 2 \\
\hline 8 & 3 & 2 & 1 & 3 \\
\hline 9 & 3 & 3 & 2 & 1 \\
\hline
\end{tabular}


Table 3: Control factors and L9 orthogonal array

\begin{tabular}{|c|c|l|c|c|}
\hline Expt.No. & $\begin{array}{l}\text { water pressure } \\
(\mathrm{Wp}) \\
\mathrm{kgf} / \mathrm{cm}^{2}\end{array}$ & $\begin{array}{l}\text { cooling rate } \\
(\mathrm{CR}) \\
{ }^{0} \mathrm{C} / \mathrm{s}\end{array}$ & $\begin{array}{l}\text { speed of } \\
\text { rolling } \\
(\mathrm{Sb}) \mathrm{mps}\end{array}$ & $\begin{array}{l}\text { Temp. of } \\
\text { bar } \\
(\mathrm{Tb}){ }^{0} \mathrm{C}\end{array}$ \\
\hline 1 & 10 & 80 & 11 & 750 \\
\hline 2 & 10 & 100 & 13 & 800 \\
\hline 3 & 10 & 120 & 15 & 850 \\
\hline 4 & 12 & 80 & 13 & 850 \\
\hline 5 & 12 & 100 & 15 & 750 \\
\hline 6 & 12 & 120 & 11 & 800 \\
\hline 7 & 14 & 80 & 15 & 800 \\
\hline 8 & 14 & 100 & 11 & 850 \\
\hline 9 & 13 & 120 & 13 & 750 \\
\hline
\end{tabular}

Table 4: Experimental Data

\begin{tabular}{|c|c|c|c|c|}
\hline Expt No. & Trial 1 & Trial2 & Trial3 & Average (YS) \\
\hline 1 & 545.1 & 560.28 & 582.9 & 562.76 \\
\hline 5 & 560.23 & 575.24 & 545.41 & 560.29 \\
\hline 7 & 580.33 & 590.26 & 577.73 & 582.77 \\
\hline 2 & 520.12 & 535.39 & 535.30 & 530.27 \\
\hline 6 & 510.24 & 520.1 & 552.82 & 527.72 \\
\hline 9 & 545.36 & 525.42 & 538.87 & 536.55 \\
\hline 3 & 565.45 & 565.34 & 509.07 & 546.62 \\
\hline 4 & 540.31 & 530.41 & 561.53 & 544.08 \\
\hline 8 & 565.42 & 585.35 & 616.56 & 589.11 \\
\hline
\end{tabular}

Table 5: Analysis of Data to find S/N Ratio

\begin{tabular}{|c|c|c|c|c|c|c|c|c|c|c|c|c|c|}
\hline \multirow[b]{2}{*}{$\begin{array}{l}\text { Expt. } \\
\text { No. }\end{array}$} & \multirow{2}{*}{$\begin{array}{l}\text { SN Ratio } \\
\text { (Larger- } \\
\text { the- } \\
\text { Better) }\end{array}$} & \multicolumn{3}{|c|}{$\begin{array}{l}\text { Water pressure } \\
(\mathrm{Wp}) \\
\mathrm{kgf} / \mathrm{cm}^{2}\end{array}$} & \multicolumn{3}{|c|}{$\begin{array}{l}\text { Cooling rate } \\
(\mathrm{CR}) \\
{ }^{0} \mathrm{C} / \mathrm{s}\end{array}$} & \multicolumn{3}{|c|}{$\begin{array}{l}\text { Speed of bar } \\
(\mathrm{Sb}) \\
\mathrm{mps}\end{array}$} & \multicolumn{3}{|c|}{$\begin{array}{l}\text { Temp. of Finish } \\
\text { rolling bar }(\mathrm{Tb}) \\
{ }^{0} \mathrm{C}\end{array}$} \\
\hline & & 10 & 12 & 14 & 80 & 100 & 120 & 11 & 13 & 15 & 750 & 800 & 850 \\
\hline 1 & 55.00 & 55.00 & & & 55.00 & & & 55.00 & & & 55.00 & & \\
\hline 2 & 54.96 & 54.96 & & & & 54.96 & & & 54.96 & & & 54.96 & \\
\hline 3 & 55.31 & 55.31 & & & & & 55.31 & & & 55.31 & & & 55.31 \\
\hline 4 & 54.49 & & 54.49 & & 54.49 & & & & 54.49 & & & & 54.49 \\
\hline 5 & 54.44 & & 54.44 & & & 54.44 & & & & 54.44 & 54.44 & & \\
\hline 6 & 54.59 & & 54.59 & & & & 54.59 & 54.59 & & & & 54.59 & \\
\hline 7 & 54.73 & & & 54.73 & 54.73 & & & & & 54.73 & & 54.73 & \\
\hline 8 & 54.73 & & & 54.73 & & 54.73 & & 54.73 & & & & & 54.73 \\
\hline 9 & 55.39 & & & 55.39 & & & 55.39 & & 55.39 & & 55.39 & & \\
\hline $\begin{array}{l}\text { Factor } \\
\text { Effects }\end{array}$ & & 55.09 & 54.51 & 54.95 & 54.74 & 54.71 & 55.10 & 54.77 & 54.95 & 54.83 & 54.94 & 54.76 & 54.84 \\
\hline $\begin{array}{c}\text { OV } \\
\text { Mean }\end{array}$ & 54.85 & & 54.85 & & & 54.85 & & & 54.85 & & & 54.85 & \\
\hline
\end{tabular}




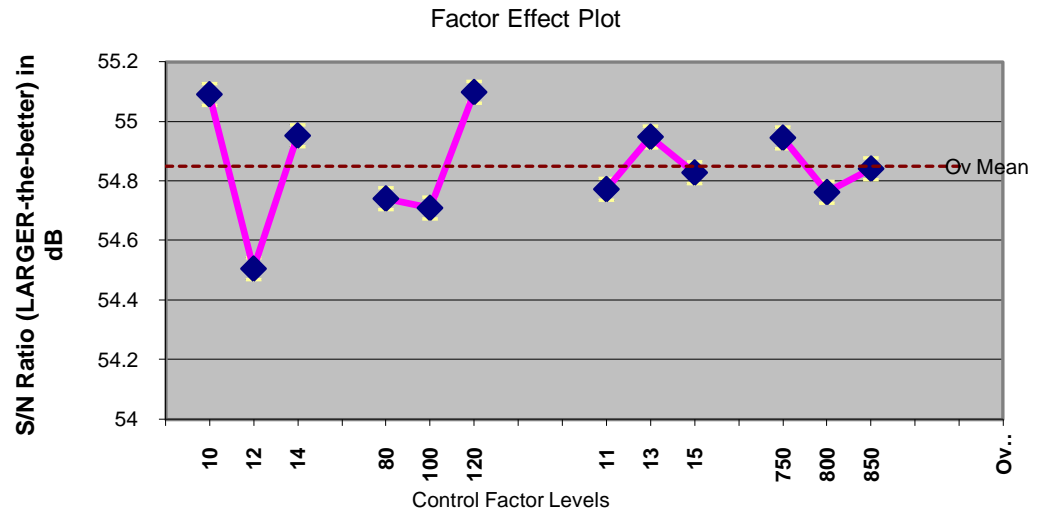

Fig.8: shows the Factor effect plot

Table6: Optimum Level of Factors and its contribution

\begin{tabular}{|c|c|c|c|c|c|c|c|c|c|}
\hline \multirow[b]{2}{*}{$\begin{array}{l}\text { Control } \\
\text { Factor } \\
\text { Names }\end{array}$} & \multicolumn{3}{|c|}{ Level } & \multirow{2}{*}{$\begin{array}{l}\text { Level } \\
\text { Name }\end{array}$} & \multirow[b]{2}{*}{$\begin{array}{l}\text { Opt } \\
\text { Level }\end{array}$} & \multirow[b]{2}{*}{$\begin{array}{c}\% \\
\text { Factor } \\
\text { Effects }\end{array}$} & \multirow{2}{*}{$\begin{array}{l}\text { Contribut } \\
\text { ion of } \\
\text { SELECT } \\
\text { ED Level } \\
\text { to S/N } \\
\text { Ratio } \\
\text { (in dB) }\end{array}$} & \multirow{2}{*}{$\begin{array}{l}\text { DOMINA } \\
\text { NT or } \\
\text { Significant } \\
\text { or } \\
\text { neutral/neg } \\
\text { ligible }\end{array}$} & \multirow[b]{2}{*}{$\begin{array}{l}\text { "F" after } \\
\text { Pooling }\end{array}$} \\
\hline & 1 & 2 & 3 & & & & & & \\
\hline $\begin{array}{l}\text { Water } \\
\text { pressure }\end{array}$ & 10 & 12 & 14 & 10 & 10 & 66 & 0.24 & $\begin{array}{llll}\mathrm{D} & \mathrm{O} & \mathrm{M} & \mathrm{I} \\
\mathrm{N} & \mathrm{A} & \mathrm{N} & \mathrm{T} \\
\end{array}$ & 280.01 \\
\hline $\begin{array}{l}\text { Cooling } \\
\text { rate }\end{array}$ & 80 & 100 & 120 & 80 & 120 & 22 & -0.11 & $\begin{array}{llll}\mathrm{D} & \mathrm{O} & \mathrm{M} & \mathrm{I} \\
\mathrm{N} & \mathrm{A} & \mathrm{N} & \mathrm{T} \\
\end{array}$ & 140 \\
\hline $\begin{array}{l}\text { Speed of } \\
\text { bar }\end{array}$ & 11 & 13 & 15 & 11 & 13 & 6 & -0.08 & $\begin{array}{c}\text { SIGNIFIC } \\
\text { ANT }\end{array}$ & 24 \\
\hline $\begin{array}{l}\text { Temp. of } \\
\text { Finish } \\
\text { rolling } \\
\text { bar }\end{array}$ & 750 & 800 & 850 & 750 & 750 & 6 & 0.10 & $\begin{array}{c}\text { SIGNIFIC } \\
\text { ANT }\end{array}$ & 25 \\
\hline
\end{tabular}

Table7: ANOVA of Experimental Data

\begin{tabular}{|l|c|c|c|l|c|}
\hline Factor & $\begin{array}{l}\text { Degree } \\
\text { of } \\
\text { freedom }\end{array}$ & $\begin{array}{l}\text { Sum of } \\
\text { squares }\end{array}$ & $\begin{array}{l}\text { Mean } \\
\text { square }\end{array}$ & $\begin{array}{l}\text { F } \\
\text { ratio }\end{array}$ & $\begin{array}{l}\% \\
\text { contribution }\end{array}$ \\
\hline $\begin{array}{l}\text { Water } \\
\text { pressure }\end{array}$ & 2 & 2259.84 & 1129.92 & 90.82 & 66.24 \\
\hline $\begin{array}{l}\text { Cooling } \\
\text { Rate }\end{array}$ & 2 & 955.45 & 477.72 & 30.40 & 21.84 \\
\hline $\begin{array}{l}\text { Speed of } \\
\text { bar }\end{array}$ & 2 & 223.02 & 111.51 & 8.96 & 6.43 \\
\hline $\begin{array}{l}\text { Finish } \\
\text { rolling } \\
\text { temp of } \\
\text { bar }\end{array}$ & 2 & 221.76 & 110.88 & 8.91 & 6.40 \\
\hline Error & 18 & 224.0 & 28 & & \\
\hline Total & 26 & 3884.075 & & & $100.000 \%$ \\
\hline
\end{tabular}




\section{Results and discussion}

Universal Testing Machine has been used to measure the Yield strength of deformed steel bar. Three readings (corresponding to the three replications) are recorded for each experimental condition as shown in Table4 .Conventionally; data from a designed experiment are used to analyze the mean objective, response function. In Taguchi Technique, the variation of the response is also examined using an appropriately chosen $\mathrm{S} / \mathrm{N}$ ratio. Broadly speaking, the $\mathrm{S} / \mathrm{N}$ ratio is the ratio of the mean (signal) to the standard deviation (noise).These $\mathrm{S} / \mathrm{N}$ ratio, derived from the quadratic loss function, is expressed on a decibel (dB) scale. The formula used to compute the $\mathrm{S} / \mathrm{N}$ ratio depends on the objective function .Generally; three standard $\mathrm{S} / \mathrm{N}$ equations are widely used to classify the objective function as, 'Larger the better', 'Smaller the better' or 'Nominal the best'. However, regardless of the type of performance characteristic a larger S/N ratio is always desirable.

In the present study, yield strength is a 'Larger the better' type of quality a characteristic since the goal is to maximize the strength. The $\mathrm{S} / \mathrm{N}$ ratio computing formula for this type of response is

$$
(S / N)=-10 \log \left(\frac{1}{n} \sum_{j=1}^{n} \frac{1}{Y_{i j^{2}}}\right)
$$

Where ' $\mathrm{i}$ ' is the number of a trial; ' $\mathrm{Y}_{\mathrm{ij}}$ ' is measured value of quality characteristics for the $\mathrm{i}^{\text {th }}$ trial and $j^{\text {th }}$ experiments; ' $n$ ' is the number of repetitions for the experimental combinations. Signal-to-noise ratios are computed using Equation (1) for each of the nine experimental conditions and are reported in Table 5. Since the experimental design is orthogonal, the factor effect can be separated out in terms of the $\mathrm{S} / \mathrm{N}$ ratio and in terms of the mean response. The average value of $\mathrm{S} / \mathrm{N}$ ratio of four control factors at each of the levels are shown in figure 8and from this the levels corresponding to the highest $\mathrm{S} / \mathrm{N}$ ratio values are chosen for each parameter representing the optimum condition. It is clear from the figure 8 that the optimum levels are A1, B3, C2and D1corresponding to water pressure $10 \mathrm{kgf} / \mathrm{cm}^{2}$ cooling rate $120^{\circ} \mathrm{C} / \mathrm{s}$ Speed of bar $13 \mathrm{mps}$, Temp of bar $750^{\circ} \mathrm{C}$.In addition to $\mathrm{S} / \mathrm{N}$ analysis, main effects of process parameters on the mean response are also analyzed. Thus the average S/N Values for each factor at three levels have been calculated shown in Table5.

The analysis of variance (ANOVA) is carried out to study the relative significance of the process parameters. The Table7 shows the computed result of the ANOVA with confidence. The F-ratio and the percentage contributions of the various parameters as quantified under the respective column of Table7 reveal that, water pressure (Wp) and Cooling Rate (CR) have significant effect on yield strength at the $95 \%$ confidence level. However, water pressure has the most significant effect on yield strength as shown by much higher F-ratio (i.e. 90.82) and also percent contribution (i.e.65.24).

\subsection{Prediction of optimum quality characteristics}

From the analysis of $\mathrm{S} / \mathrm{N}$ ratio and the mean response characteristic, the optimum level of the control factors are determined as A1,B3,C2 and D1.Hence the predicted mean of the quality characteristic (yield strength)has been computed as shows below

The optimum levels of each parameter from mean effect diagram are $\mathrm{YS}_{\mathrm{A} 1}, \mathrm{YS}_{\mathrm{B} 3}, \mathrm{YS}_{\mathrm{C} 2}, \mathrm{YS}_{\mathrm{D} 1}$

$$
\begin{aligned}
& \left.\mathrm{YS}_{\mathrm{opt}}=\mathrm{YS} \text { mean+( } \mathrm{YS}_{\mathrm{A} 1}-\mathrm{YS}_{\text {mean }}\right)+\left(\mathrm{YS}_{\mathrm{B} 3}-\mathrm{YS}_{\text {mean }}\right)+\left(\mathrm{YS}_{\mathrm{C} 2}-\mathrm{YS}_{\text {mean }}\right)+\left(\mathrm{YS}_{\mathrm{D} 1}-\mathrm{YS}_{\text {mean }}\right) \\
& \mathrm{Where}_{\mathrm{YS}} \mathrm{YS}_{\text {mean }}=553.35 \mathrm{~N} / \mathrm{mm}^{2}, \mathrm{YS}_{\mathrm{Al}}=558.61 \mathrm{~N} / \mathrm{mm}^{2}, \\
& \mathrm{YS}_{\mathrm{B} 3}=569.47 \mathrm{~N} / \mathrm{mm}^{2}, \mathrm{YS}_{\mathrm{C} 2}=539.89 \mathrm{~N} / \mathrm{mm}^{2}, \mathrm{YS}_{\mathrm{D} 1}=554.8661 \mathrm{~N} / \mathrm{mm}^{2} \\
& \mathrm{YS}_{\mathrm{opt}}=553.35+(558.61-553.35)+(569.47-553.35)+(539.89-553.35)+(554.86-553.35) \\
& \mathrm{YS}_{\mathrm{opt}}=587.83 \mathrm{~N} / \mathrm{mm}^{2}
\end{aligned}
$$

An important step in Taguchi's optimization technique is to conduct confirmation experiment for validating the predicted result. Thus $95 \%$ confidence interval (CI) for the predicted mean of optimum QC on a confirmation test is estimated using the following two equations

$$
\mathbf{C I}=\sqrt{f(0.05 ; 1 ; f e) * V e *\left(\frac{1}{N e f f}+\frac{1}{r}\right)}
$$

And $\quad N_{e f f}=\frac{N}{1+T_{D O F}}$

Where, $\mathrm{F}(\alpha, 1, f e)$ is the F-ratio required for $100(1-\alpha)$ percent confidence interval, $f \mathrm{e}$ is $\mathrm{DOF}($ Degree of freedom) for error variance, $\mathrm{R}$ is number of replication for confirmation experiment and $N_{\text {eff }}$ is the effective number of replication.N is total number of experiments [i.e.27] and $T_{D O F}$ is total degree of freedom [i.e.8], from 
ANOVA Table we have $\mathrm{V}_{\mathrm{e}}=224.0, f e=18$ and standard statistical Table the required F-ratio for $\alpha=0.05$ is $\mathrm{F}(0.05,1,18)=4.41$,Substituting these values in equation (2) and (3), the calculated confidence interval is ;

$N_{\text {eff }}=\frac{27}{1+8}=3$,

$=\sqrt{4.41 * 224 * 0.66}$

$\mathrm{CI}= \pm 25.53$

Thus the $95 \%$ confidence interval of the predicted optimal yield strength is obtained as;

Predicted $\mathrm{YS}=\mathrm{YS}_{\mathrm{opt}} \pm \mathrm{CI}$

Predicted YS $=587.83 \pm 25.53$

Predicted $Y S=562.3$ to $613.36 \mathrm{~N} / \mathrm{mm}^{2}$

i.e. $562.3 \mathrm{~N} / \mathrm{mm}^{2}<Y S<613.36 \mathrm{~N} / \mathrm{mm}^{2}$

\subsection{Confirmation test}

The confirmation test is the final step in the first iteration of the design of the experiment process. The purpose of the confirmation experiment is to validate the conclusions drawn the analysis phase. The confirmation experiment is performed by conducting a test with a specific combination of the factors and levels previously evaluated. In this study, after determining the optimum conditions and predicting the response under these conditions, a new experiment was designed and conducted with the optimum levels of the quenching process parameters. A confirmatory test was performed after the optimal control factor setting was determined. The confirmatory test is a repetition of the experiment, to investigate Yield strength of steel bar with the control factors set at optimal setting to achieve the predicted quality characteristics. Three trials at the optimal control factor setting were made in confirmatory test are presented in Table 6.

\section{Confirmatory test by calculated Yield strength values (YS)}

The model equation for Yield strength we have,

YS=885.111 Wp $\mathrm{p}^{-0.0467} \mathrm{CR}^{0.0957} \mathrm{Sb}^{0.0260} \mathrm{~Tb}^{-0.1289}$

Table6: Confirmatory test by calculated Yield strength values

\begin{tabular}{|c|c|c|c|c|c|c|}
\hline Trial & $\begin{array}{l}\text { Water } \\
\text { pressure } \\
(\mathrm{Wp})\end{array}$ & $\begin{array}{l}\text { Cooling } \\
\text { rate } \\
(\mathrm{CR})\end{array}$ & $\begin{array}{c}\text { Speed of } \\
\text { bar } \\
\text { (Sb) }\end{array}$ & $\begin{array}{c}\text { Temp of } \\
\text { bar before } \\
\text { quenching } \\
\text { (Tb) }\end{array}$ & $\begin{array}{c}\text { Yield strength } \\
\text { Calculated by } \\
\text { Using model } \\
\text { equation } \\
\text { YS }= \\
\text { k. Wp } \\
\mathrm{Wp}^{\mathrm{m}} \cdot \mathrm{CR}^{\mathrm{m} 2} \text {. } \\
\mathrm{Sb}^{\mathrm{m} 3} \cdot \mathrm{Tb}^{\mathrm{m} 4}\end{array}$ & Average \\
\hline 1 & 10 & 120 & 13 & 750 & 572.324 & \multirow{3}{*}{572.324} \\
\hline 2 & 10 & 120 & 13 & 750 & 572.324 & \\
\hline 3 & 10 & 120 & 13 & 750 & 572.324 & \\
\hline
\end{tabular}

\section{Confirmatory test by measured Yield strength values (YS) using experimentation}

Table7: Confirmatory test by measured Yield strength values

\begin{tabular}{|c|c|c|c|l|l|l|l|l|}
\hline Trial & $\begin{array}{l}\text { Water } \\
\text { pressure } \\
\text { (Wp) }\end{array}$ & $\begin{array}{l}\text { Cooling } \\
\text { rate } \\
(\mathrm{CR})\end{array}$ & $\begin{array}{l}\text { Speed } \\
\text { of bar } \\
(\mathrm{Sb})\end{array}$ & $\begin{array}{l}\text { Finish } \\
\text { rolling } \\
\text { temp of } \\
\text { bar(Tb) }\end{array}$ & Obs.1 & Obs.2 & Obs.3 & Average \\
\hline 1 & 10 & 120 & 13 & 750 & 571.86 & 571.03 & 572.48 & 571.79 \\
\hline 2 & 10 & 120 & 13 & 750 & 571.25 & 569.71 & 569.85 & 570.27 \\
\hline 3 & 10 & 120 & 13 & 750 & 574.40 & 570.64 & 570.45 & 571.83 \\
\hline
\end{tabular}


Improvement in Yield Strength of Deformed Steel Bar by Quenching using Taguchi Method

The average of actual Yield strength values from above tables are lies between Confidence Interval Level These lies between the limit of $95 \%$ CI specified as $562.3 \mathrm{~N} / \mathrm{mm}^{2}$ to $613.36 \mathrm{~N} / \mathrm{mm}^{2}$. Hence it confirmed the result for optimum parameter setting.

\author{
4.3Improvement in yield strength \\ We have $Y S_{\text {mean }}=553.35 \mathrm{~N} / \mathrm{mm}^{2}$ and $Y_{\text {opt }}=587.83 \mathrm{~N} / \mathrm{mm}^{2}$ \\ $\%$ Improvement in $\mathrm{YS}=\frac{\mathrm{YS} \mathrm{opt}-\mathrm{YS} \text { mean }}{\mathrm{YS} \text { mean }}$ \\ $\%$ Improvement in YS $=\frac{587.83-553.35}{553.35}=6.23 \%$ \\ Improvement in yield strength $=\frac{6.23 * 553.35}{100}$ \\ Improvement in yield strength $=34.47 \mathrm{~N} / \mathrm{mm}^{2}$
}

\title{
4.4Robust design
}

A main cause of poor yield in manufacturing processes is the manufacturing variation. These manufacturing variations include variation in temperature or humidity, variation in raw materials, and drift of process parameters. These sources of noise/variation are the variables that are impossible or expensive to control. The objective of the robust design [1] is to find the controllable process parameter settings for which noise or variation has a minimal effect on the product's or process's functional characteristics. For each experiment of the inner array, a series of new experiments are conducted by varying the level settings of the uncontrollable noise variables. The level combinations of noise variables are done using the outer orthogonal array. The influence of noise on the performance characteristics can be found using the ratio [1] Using this result, it is possible to predict which control parameter settings will make the process insensitive to noise factors.

\subsection{Experimental observation}

After obtaining and analyzing the experimental data when steel undergoes water cooling is in setting up the test, an experimentally measured surface temperature decrease in terms of the water pressure on the water filled tube, while the other variables such as stock transporting speed and stock size are fixed. The tube length is $4.9 \mathrm{~m}$. It shows that the bigger the water pressure, the higher the cooling capacity. Also indicate that when the distance between the inside wall of the tube and the bar surface increased, the temperature drop decreases, i.e., the cooling capacity decreases. The cooling efficiency of the cooling system is linearly dependent on the water flow rate supplied to the cooling tube at a critical water pressure, but the temperature drop, i.e., the cooling efficiency, starts slowing down following the critical water pressure. A further increase in water pressure leads to a small additional temperature drop. Hence one may not need to increase the water pressure recklessly to increase the temperature drop of stock during water cooling.

\section{Conclusions}

The following conclusions has been drawn from the experimental study of quenching process, that the cooling rate of hot bar in quenching process is affected by temperature drop during rolling process, hence the quality deviates from mean. To minimize this effect on response variable that is yield strength, we need to control the water pressure at a level according to temperature drop in rolling process. Also it is concluded that the effect of temperature drop can be controlled by controlling water pressure in quenching process, by keeping the speed of rolling constant. Optimization of process parameters were performed by experimentation using Taguchi Method. The selected process parameters along with their levels for experimentation were as water pressure 10, 12, $14 \mathrm{kgf} / \mathrm{cm}^{2}$ Cooling rate $80,100,120^{\circ} \mathrm{C} / \mathrm{s}$ Speed of bar 11, 13, $15 \mathrm{mps}$ and Temp of bar 750, 800, $850{ }^{0} \mathrm{C}$ respectively.

The following conclusions have been drawn from the present work.

1. Among the four process parameters ,the water pressure and cooling rate were having significant effect on the quality characters that is YS .More ever water pressure was having the highest contribution of the order $66 \%$

2. The optimum levels of the process parameters were found to be A1,B3,C2and D1corresponding to water pressure $10 \mathrm{kgf} / \mathrm{cm}^{2}$, cooling rate $120{ }^{\circ} \mathrm{C} / \mathrm{S}$, Speed of bar $13 \mathrm{mps}$, Temperature of bar $750{ }^{0} \mathrm{C}$

3. Optimum value of Yield Strength for $95 \%$ CI was predicted as $(587.83 \pm 25.53) \mathrm{N} / \mathrm{mm}^{2}$ i.e. YS lies between 562.31 to $613.36 \mathrm{~N} / \mathrm{mm}^{2}$ i.e. $562.31 \leq \mathrm{YS} \leq 613.36$ 
4. From confirmation experiments the mean value of the YS corresponding to the optimum conditions was obtained as $565.29,570.27$ and $571.83 \mathrm{~N} / \mathrm{mm}^{2}$ when fall within the predicted range.

5. Thus the prediction made by Taguchi parameter design technique were in good agreement with the confirmation results

6. Thus the result of present investigation is valid within the specified range of the process parameters along with their chosen levels and for specific combination of carbon percentage

Design of experiment (DOE) using Taguchi method has been applied to improve the yield strength by quenching process for deformed steel bar. Also from micro-structure analysis we conclude that the process of quenching causes hard surface due to martensite structure formed. It has been observed that after quenching, the structure clearly shows the presence of tempered low carbon martensite along with bainite. These two phases are responsible for the increase in the hardness value of deformed steel bar. Hence the Yield strength of bar is improved. It is suggested that the DOE by Taguchi Method is easy and cheapest to use for improvement in Yield strength of deformed steel bar.

\section{Future scope}

The process parameter variation can cause the variation in quality, so the future scope of this research will be to control the quenching process parameters of deformed steel bar accurately by using computer control system to minimize variation in process. The research should be done for every size of bar, and for many rolling speeds for variety of steel chemical composition specified by IS-1786 specification. This will help to make robust process design of quenching process to improve quality. The operating data for this process should be made available for all rolling mills to control the quenching process to get always the desired quality of deformed steel bar.

\section{Acknowledgement}

The authors acknowledge to the Rajuri steels Pvt. Ltd. M.I.D.C. Jalna, Maharashtra State, India for cooperation and the technical assistance.

\section{References}

[1] Douglas E. Montgomery, Design and Analysis of Experiments (Third Edition, John Wiley and sons, 1991) 13-16,363, 367-368,49049

[2] Young Lee, Rod and Bar Rolling (Marcel Dekker, Inc. New York, Besal, 2004) 71,310-313

[3] T.V. Rajan, C.P.Sharma, "Heat Treatment, Principal and techniques", Pentice-Hall of India, New Delhi, 1997, pp.111-112, $130,145-146$

[4] Thermex Technical Document (H\&K Rolling Mill Engineers Pvt.Ltd. 2003) 9, 14, 18

[5] William Roberts, Hot Rolling of Steel, 2005, 621-623

[6] Serope Kalpakjain, Manufacturing Engineering and Technology (Pearson education, 2000) 121-122

[7] Validmir B. Ginzburg, Steel-Rolling Technology Theory and practice, (Marcel dekkar, Inc, New Yark, 2005) 131-132. 